\title{
THE RENOVATION OF THE LOWER WOODLAND GARDEN AT THE ROYAL BOTANIC GARDEN EDINBURGH
}

\author{
Robert Unwin ${ }^{1}$
}

\begin{abstract}
The origins and history of the Lower Woodland Garden at the Royal Botanic Garden at Edinburgh are described along with the rationale for their restoration. The concept of a Stumpery or Rootery, a precursor to the Peat Walls, is also described. The method of restoration, reconstruction and replanting of the area is discussed and examples of species planted in the area are given.
\end{abstract}

\section{INTRODUCTION}

The area of the Royal Botanic Garden Edinburgh (RBGE) which is now referred to as the Lower Woodland Garden provides a north-facing, shady habitat for growing choice woodland species. The area has been used for cultivating and displaying plants from the cool temperate regions of Asia since the beginning of the 20th century. At that time there was an influx of new and interesting plants which caused great interest among horticulturists and the gardening public of the time. These were brought in by collectors such as George Forrest and Reginald Farrer. The Lower Woodland Garden area provided the ideal cool, shady growing conditions for these species in the relatively dry climate of the east coast of Scotland. An area was developed facing north and changed in design from a Stumpery in the late 1920s and early 1930s, to the Peat Walls later in the 1930s and finally to the area that is known today as the Lower Woodland Garden. The terracing, using peat blocks as walling to contain moisture-retentive soil, has been a feature of the Woodland Garden at the Edinburgh Garden since the 1930s. Recently, the area has been completely renovated in an attempt to solve a pernicious weed problem caused by Cymbalaria hepaticifolia and to provide opportunities to display newly collected and acquired species. As well as the renovation and display of newly collected species, the plantings are accompanied by interpretation to inform visitors about these plants.

\section{HISTORY AND BACKGROUND}

In fern-crazed Victorian Britain in the early 1900s it became extremely popular to use tree roots to create a Stumpery as a garden feature. The first one was built in Staffordshire in 1856 at Biddulph Grange and was designed by Edward William Cooke (Hayden, 1989). The Stumpery at RBGE (Fig. 1) provided a habitat which was ideal for shrubs

1. Robert Unwin is a Senior Horticulturist in the Alpine Department at the Royal Botanic Garden Edinburgh. Address: 20A Inverleith Row, Edinburgh, EH3 5LR.

Email: R.Unwin@rbge.org.uk 
such as the smaller species of Rhododendron and other dwarf ericaceous shrubs such as Vaccinium and Gaultheria species. From records we know that these grew alongside Rodgersia, Paeonia and Primula species (Evans, 1974). Many of the plants that are now grown in the Lower Woodland Garden would have been found in the Rock Garden, in a cool glasshouse or in the Stumpery. The Stumpery was an interesting feature of the Garden which was removed soon after the Peat Walls were developed in the 1930s. Prior to the creation of the Peat Walls many of the plants which thrived in a semi-shaded, north-facing environment were cultivated in the Stumpery, which was sometimes also referred to as a Rootery. This precursor to the Peat Walls had terraces of soil which were retained by upturned tree root plates, creating planting pockets and microclimates suitable for cultivating choice woodland species. In the area that used to be referred to as the Peat Walls the soil terraces are now contained by peat blocks instead of tree stumps.

This area is now called the Lower Woodland Garden and has been redeveloped over the last seven years. A terracing structure using both peat blocks from sustainable sources and tree stumps has been incorporated into the design because it was considered important to refer back to the Victorian tradition and history of the plant display while at the same time using more sustainable materials when updating it.

The early part of the 20th century must have been a wonderfully exciting time for the keen gardener and intrepid plant collector. Plant collectors such as George Forrest,

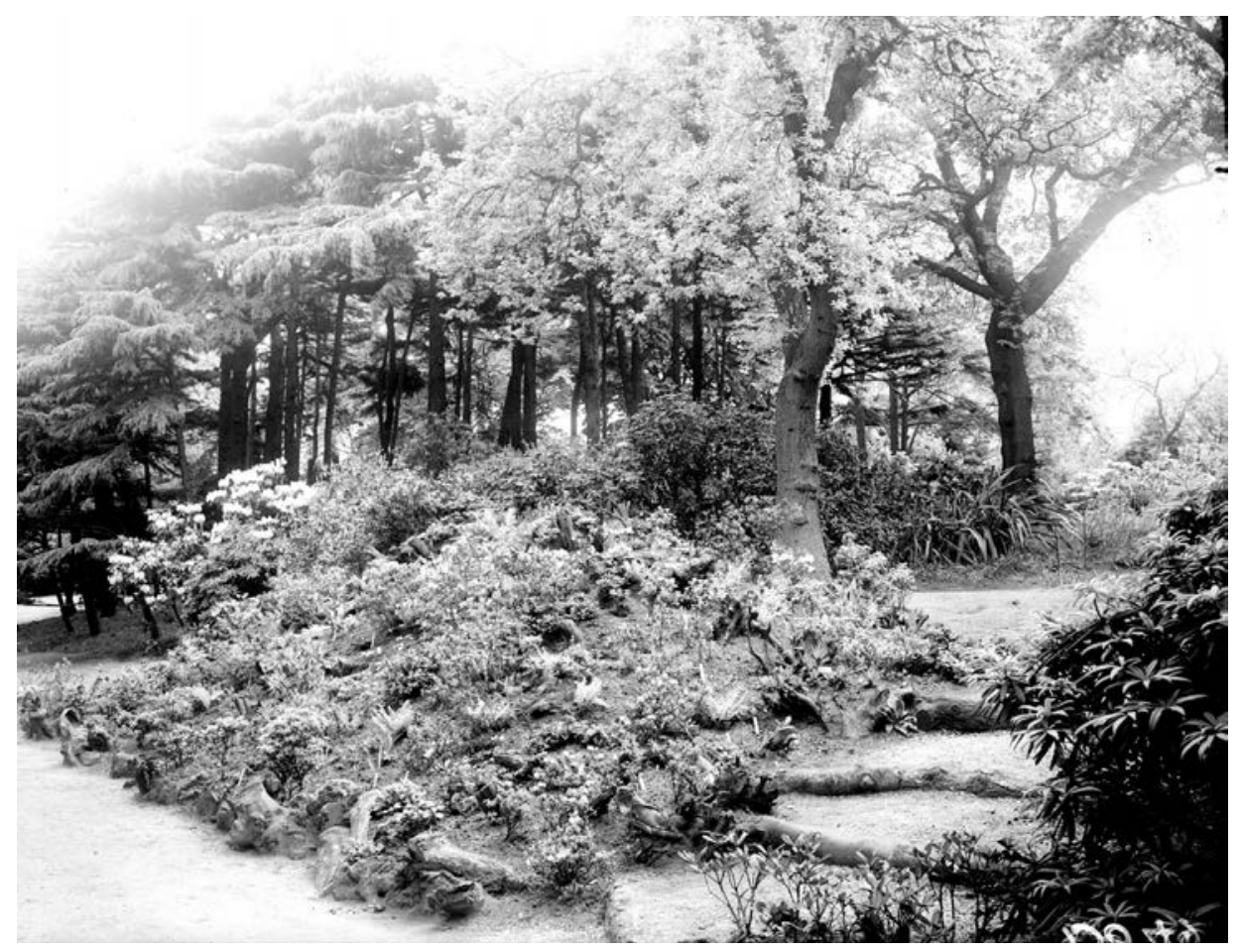

Fig. 1 The Stumpery at RBGE in 1930. Image: RBGE Library and Archives. 
Frank Kingdon-Ward and Reginald Farrer were at the height of their explorations. As a consequence introductions of many new plants into Britain were at an all-time high with exciting new species of Rhododendron, Primula, Gentiana, orchids and many other genera flooding into British gardens.

At this time, Logan Garden in south-west Scotland was owned by the McDouall brothers, Kenneth and Douglas (Fig. 2). Sadly, there are very few records surviving from this period but circumstantial evidence strongly suggests that the McDoualls helped to sponsor several plant-collecting trips. Today their garden is divided into two, RBGE at Logan and Logan House Garden. In their collections there are several champion specimen trees and rhododendrons dating back to the turn of the 20th century.

The use of peat blocks to construct terraces was first referred to in 1927 in an article written by Kenneth McDouall on Logan Garden, published in the Journal of the Royal Horticultural Society. He describes the cultivation of the rhododendrons they raised from seed collected by Forrest and Farrer:

The peat terraces were made especially for these brilliant flowered little Rhododendrons, so that they may be seen and appreciated. There are six terraces, with walls 18 inches high, built of peat cut from the bog in large slabs and placed one on top of the other when wet. Each species of Rhododendron is planted thickly together, and all were raised from seed collected by Forrest and Farrer. Lillies, Meconopsis, Primulas and a few other plants are grown among them.

(McDouall, 1927)

The author also noted that 'The peat walls seem to keep the borders moist and at the same time give sufficient drainage'.

From my childhood at Logan I specifically remember one of the largest Rhododendron macabeanum in the country growing in Logan House Garden, which probably dates back to Kingdon-Ward's original introduction from India in 1928. The practice of sponsoring plant collectors in return for a share of the seed they collected was commonplace amongst wealthy landowners at this time. During George Forrest's plant-hunting career in China from 1904 to 1932, 46 different sponsors are documented as having contributed to his travels. For his seventh and final expedition in 1930 Kenneth McDouall is listed as a seed sponsor who contributed $£ 150$ (McLean, 2004). The McDoualls’ repayment for the financial support they provided to Forrest was a selection of the new plant introductions which he had managed to return home with. Many of these introductions needed specific conditions for successful cultivation and it is set against this background that the use of peat to create terraces, or what became known as the Peat Walls, was first developed (Fig. 3).

Such was the success of this means of cultivating these exciting new plants that the concept spread. Inspiration to develop the Peat Walls at RBGE came from a visit to Logan by senior staff in the early 1930s (Evans, 1974). The Peat Walls were constructed 
during the 1930s (Fig. 4) and provided ideal growing conditions for many of these dwarf shrubs and plants not only from China and the Himalayas but also from New Zealand, North America and Japan. The project to construct a garden of peat blocks exceeded the wildest dreams of the instigators and this terracing structure has been a feature of the Lower Woodland Garden ever since their first construction. However, an invasive weed problem had been getting steadily worse, and in 2007 , the decision was made to tackle the problem and to redevelop the area. As a result it was home to a minimal collection of plants from then until 2012, when the area started to be replanted and the collection began to expand again.

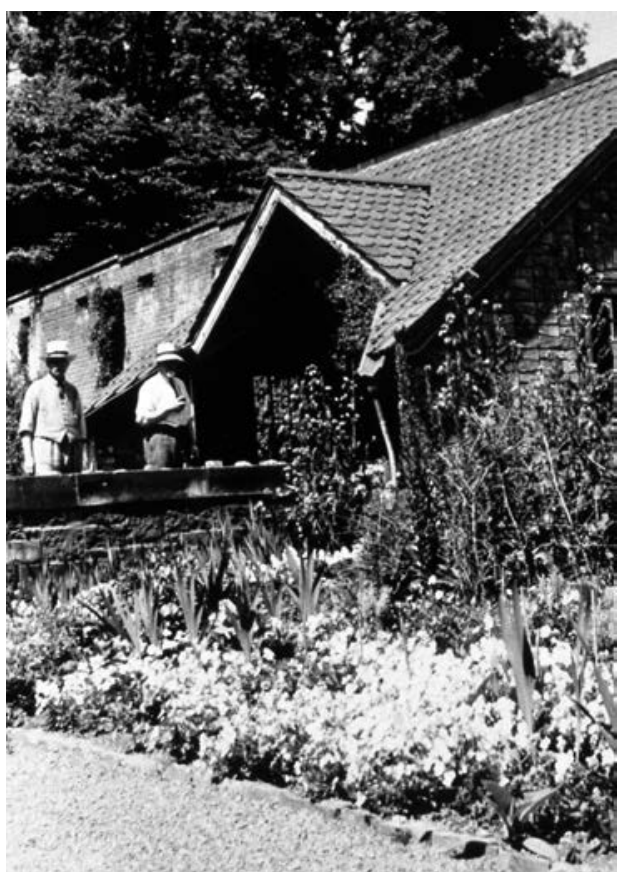

Fig. 2 The McDouall brothers at Logan Garden c. 1940. Image: RBGE Library and Archives.

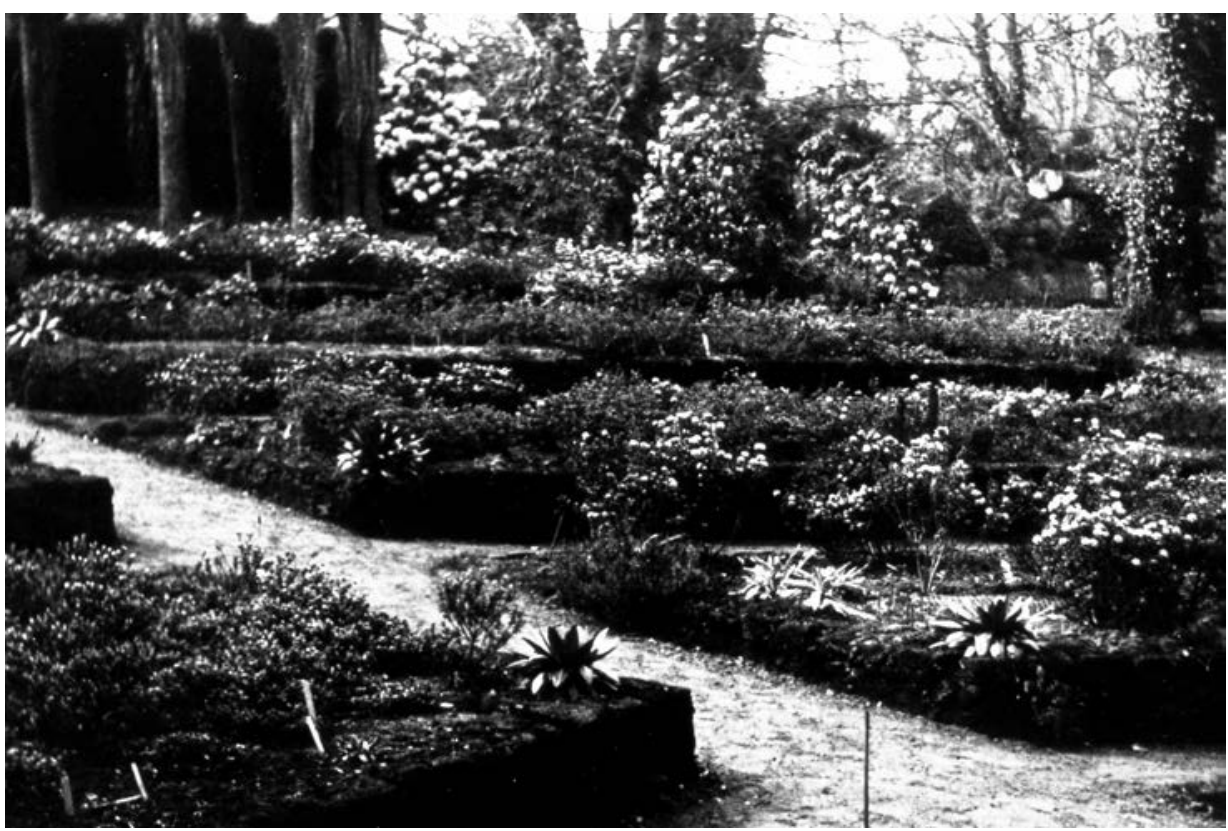

Fig. 3 The Peat Walls established by the McDouall Brothers at Logan in 1927. This became the blueprint for the creation of the Peat Garden at RBGE. Image: RBGE Library and Archives. 


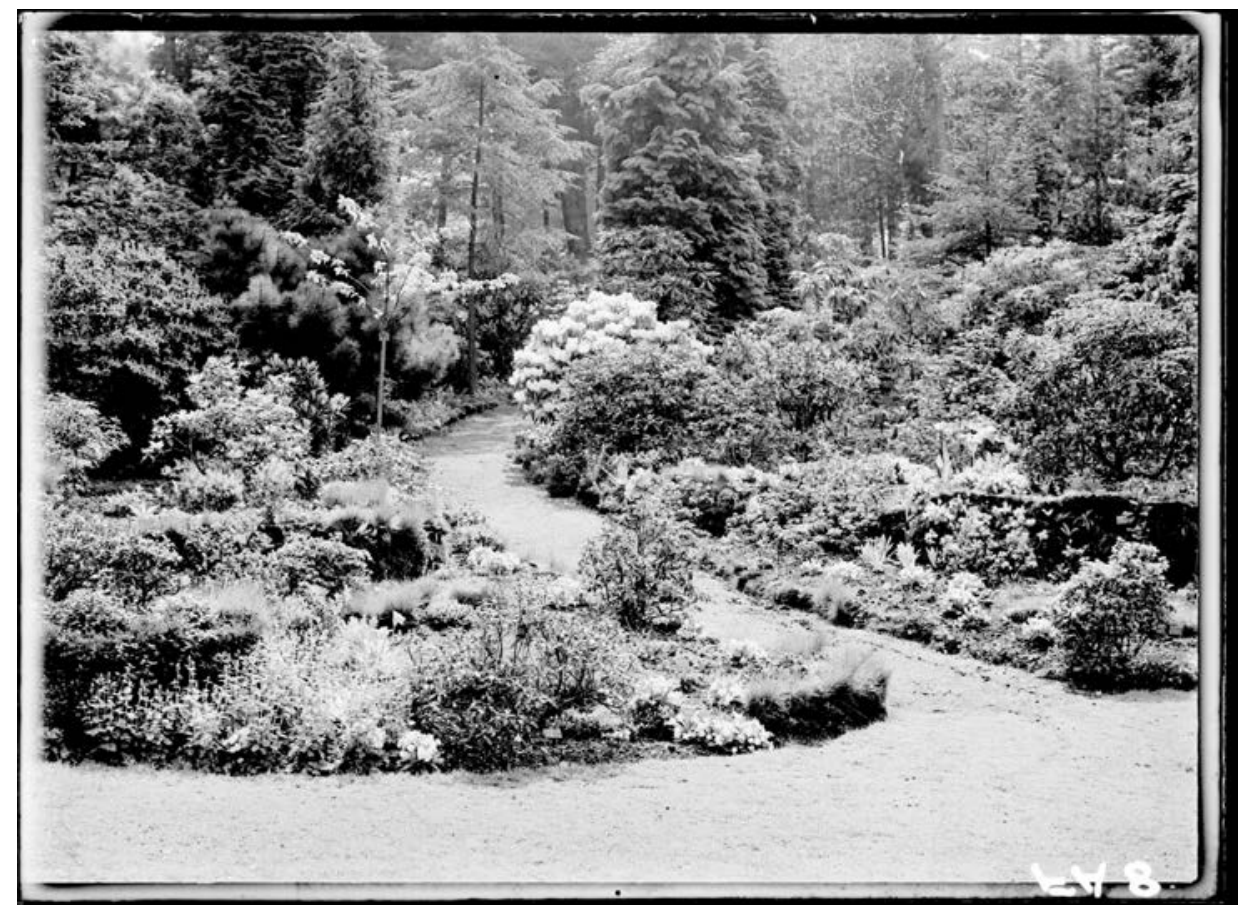

Fig. 4 The Peat Walls at RBGE in the 1930s. Image: RBGE Library and Archives.

\section{REDEVELOPMENT}

After several years of renovation work the redevelopment of the Lower Woodland Garden is now entering its final stage and being planted up. The first task in the redevelopment of the area was the eradication of a small but particularly invasive weed, Cymbalaria hepaticifolia, which has mats of white creeping roots (Figs $5 \& 6$ ). It also has the ability to regrow from the shortest length of root imaginable, even from a piece just a few millimetres in length. Years of hand-weeding proved futile in controlling it as the roots permeated the roots of the woody and herbaceous plants. Without actually naming it specifically, Alfred Evans (Assistant Curator at RBGE from December 1939 to May 1985) in his classic book, The Peat Garden and its Plants (Evans, 1974), refers to 'a race of weeds, the pernicious, creeping, stoloniferous kind, which quite quickly make weeding a nightmare' when specifically talking about peat gardening. This description matches the behaviour of $C$. hepaticifolia particularly well and we can safely assume from this that it has been causing problems for horticultural staff at RBGE for many decades.

The first task in the redevelopment project was to clear the area so that the ground could be fallowed over the forthcoming seasons and to allow the use of a systemic herbicide to rid the area of the Cymbalaria. Ferns, herbaceous and bulbous plants such as Trillium, Arisaema and Iris species were lifted from the area and taken to the nursery. 


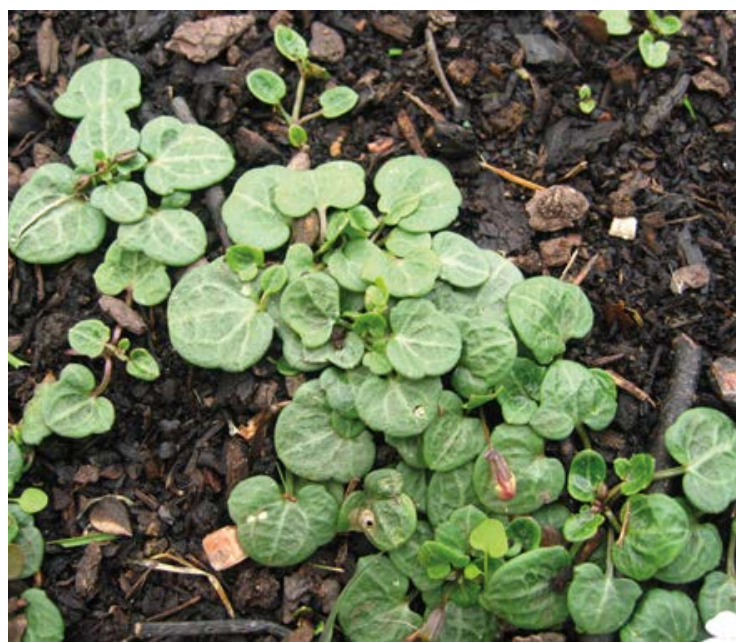

Fig. 5 Cymbalaria hepaticifolia. Photo: Robert Unwin.

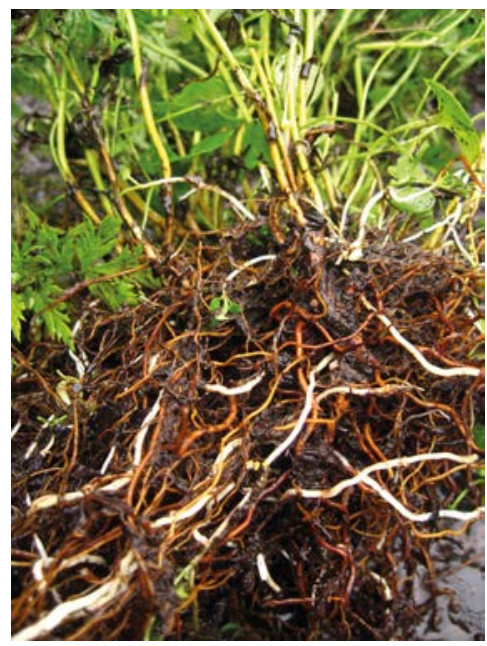

Fig. 6 Adonis brevistyla with $C$. hepaticifolia entwined. Photo: Robert Unwin.

Here they were carefully washed and cleaned to remove all the roots of the weed. This proved to be a laborious task for many of the more delicate species such as Ranzania japonica (Fig. 7), a delicate herbaceous member of Berberidaceae, Paris japonica (Fig. 8) and Adonis brevistyla, as the weed roots had entwined themselves into the roots and crowns of these plants. These clean plants were then grown in pots for several seasons in a shade tunnel to ensure that they were weed free. This cleaning process was repeated for any plants which were found to be harbouring the weed. In order to retain the wild

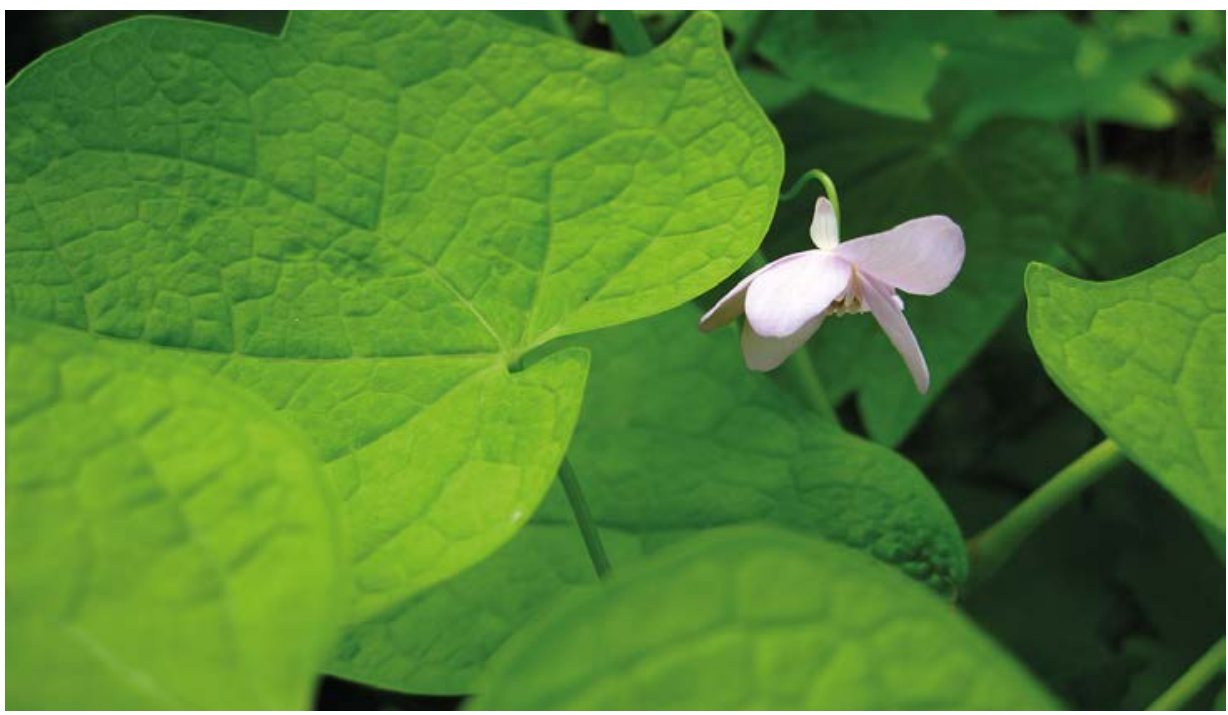

Fig. 7 Ranzania japonica. Photo: Robert Unwin. 


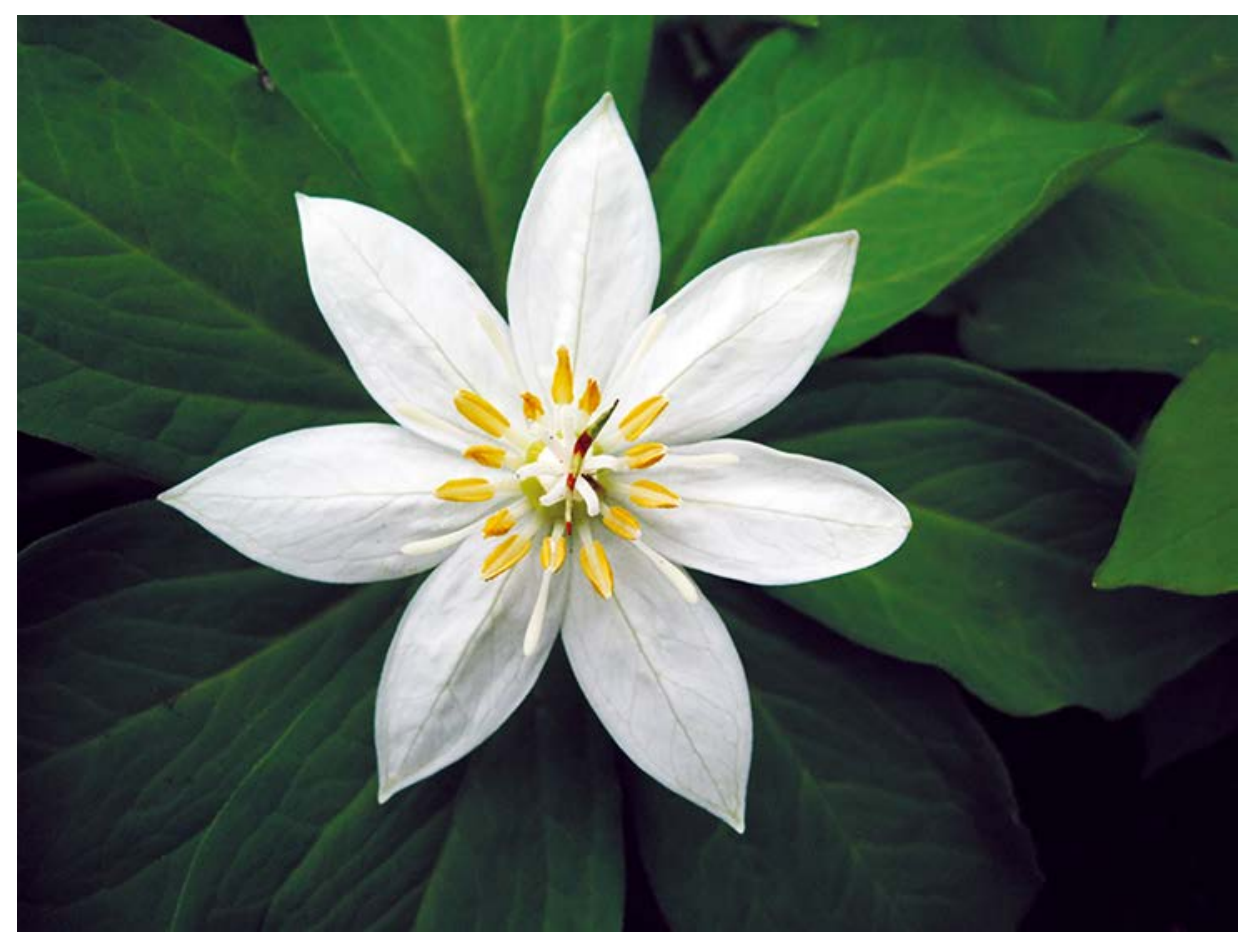

Fig. 8 Paris japonica. Photo: Robert Unwin.

collected status of the Living Collection the woody plant species such as Rhododendron, Vaccinium and Gaultheria were propagated vegetatively from cuttings, layers and suckers. Only after these propagules were successfully established were the parent plants removed. The few woody plants that failed to propagate were lifted and grown in large pots in the nursery in order that further attempts to propagate them could be made.

Several structurally important large shrubs were retained in the beds including a group of Pieris formosa, Fothergilla major and Richea scoparia. Successful attempts were made to kill the weed around these using the careful application of herbicide to the Cymbalaria under these plants. In all other areas a combination of hand-weeding and repeated applications of herbicide over several years eventually eradicated the weed, leaving the area ready to replant. To improve visitor access a system of new paths was constructed throughout the area at the same time. In recent years, there has been a trend away from using grass paths in the Garden due to increasingly wet summer weather making this surface unusable and impractical. Concerns over biosecurity and phytosanitary issues have also made grass unpopular, because muddy paths have been linked to the spread of Phytophthora species. With this in mind, paths surfaced with a hardwearing cover called Cedec ${ }^{\circledR}$ have been used through the area, thus hopefully reducing the opportunity for diseases which can harbour in mud and can then be spread around the Garden and on to other gardens by the footfall of visitors. 
Due to the current sensitivities surrounding the use of peat in horticulture careful consideration was taken in the redevelopment as to whether peat blocks should be used to create the terraces as before. Given the historical importance and ideal growing environment that peat provides it was decided to keep the tradition of peat gardening alive and that a limited number of peat blocks should be used. Approximately 500 blocks of peat were used in the construction of the new terraces. These have been made from Scandinavian peat sourced from Sweden. This peat is said to be sustainable as it grows quickly and its use is approved and licensed by the Swedish authorities. Unlike the traditional, locally sourced Scottish peat blocks which were historically used these Swedish blocks are formed from a younger peat and have a more fibrous texture which makes them suitable for growing plants directly in the blocks. We have found they provide the perfect growing environment for species such as Shortia uniflora, Shizocodon soldanelloides and Pleione pleioniodes. In his writings of 1927, Kenneth McDouall never mentioned growing any plants directly in the peat blocks themselves. We can only speculate that this may have been due to the dense structure of the peat blocks used at that time, which were perhaps not suitable for growing plants in directly.

The peat blocks arrived at RBGE from the supplier in 2012 and were found to be dehydrated, very light indeed and perfect for handling. In this dry state the blocks, which roughly resemble a breeze block in size (approximately $20 \mathrm{~cm} \times 20 \mathrm{~cm} \times 40 \mathrm{~cm}$ ), are

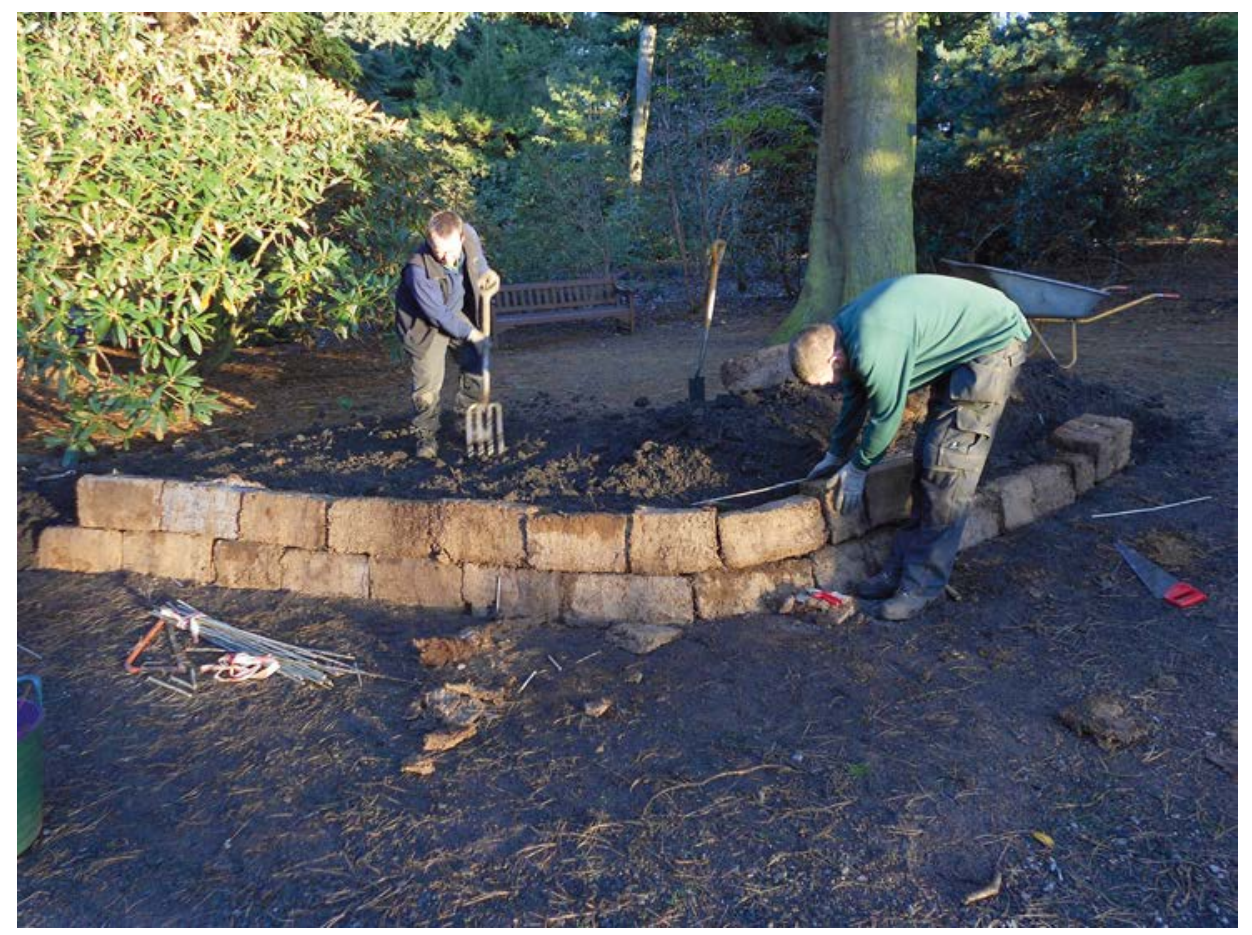

Fig. 9 Peat Wall construction. Photo: David Knott. 
easily cut and shaped to form the desired curve using a joiner's saw. The blocks were carefully positioned on the soil, creating the curve and angle, then fresh green bamboo canes cut from plants in the Garden were hammered in to keep the blocks in place. It is important to ensure that adjoining blocks butt up as close as possible to each other. Once in position the soil is back-filled to the level of the top block. In the wet summer of 2012, the blocks quickly soaked up moisture from their environment without the need for additional irrigation.

The blocks help to retain the moisture in the terraced soil and provide ideal conditions for many choice woodland plants. Any remaining plants in the Nursery which were originally growing in the area were replanted into the new beds in the spring of 2012. Over the preceding years many other plants had been removed from the Peat Walls and had been planted elsewhere in the Woodland Garden. This was done only

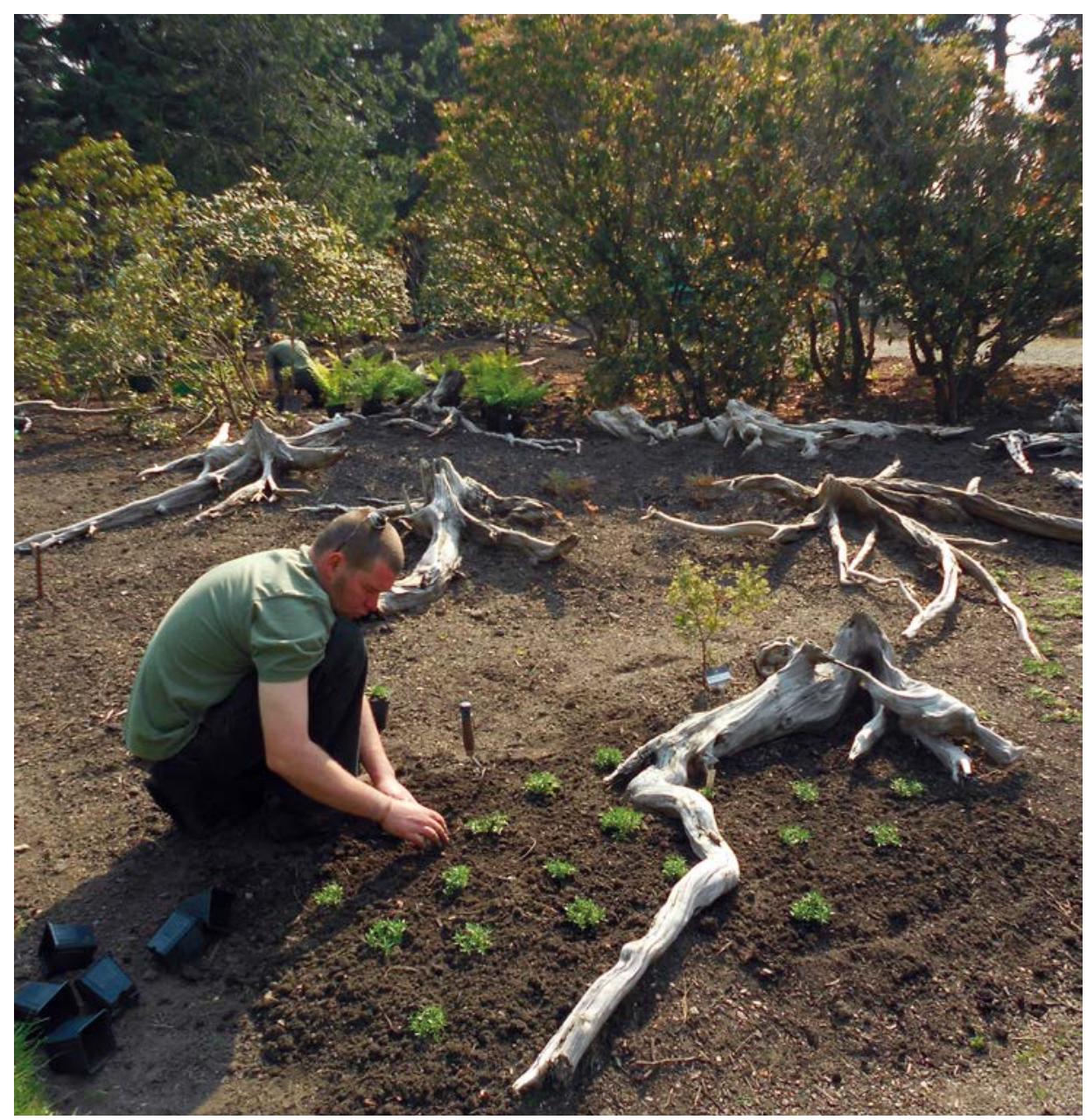

Fig. 10 Planting up the new Stumpery. Photo: David Knott. 
once they had been established in a pot and had proven to be free from Cymbalaria. Many of these have now been relocated back to the Lower Woodland Garden. One of the highlights of the area is a wonderful collection of species and hybrid Cypripedium kindly donated from a nursery in Germany. These popular plants are under threat in their native habitat because plants growing in the wild are dug up and shipped to buyers all over the world, giving no opportunity for the wild populations to regenerate. The nursery in Germany propagates and sells cultivated plants, removing the need to dig up wild plants and providing a sustainable source for growers to safely buy and cultivate them. Interpretation has been installed in the Lower Woodland Garden describing this process and this helps to highlight the plight of Cypripedium in the wild. Seramis ${ }^{\circledR}$ has been incorporated into the area where the Cypripedium are planted. This is a clay granule which helps to retain moisture while also providing a well-drained medium for them to grow.

In other parts of the Lower Woodland Garden terraces have been created using oak limbs from a huge Quercus robur tree which was sadly lost in the gales of 3 January 2012 when winds gusting at over 100mph devastated much of the Garden and glasshouses. These terraces now support a collection of Primula in section Petiolares. This has reduced the amount of peat blocks required and also demonstrates other methods of terracing soil to best display plants (Fig. 10).

In an attempt to recreate the Stumpery of the past, an area has been included in the redevelopment using bleached stumps and roots of Pinus sylvestris recovered from a reservoir in north-west Scotland. The pockets between stumps are probably best described as a hybrid between an ancient forest floor and a man-made Stumpery. This is the perfect habitat for displaying ferns, trilliums, gentians and many other interesting plants.

\section{NEW PLANTINGS}

As material from recent collecting trips reaches planting size we will continue to plant up these areas. Already some plants from one of my own trips to North Carolina in 2011 (collector code USMWST) have been planted out including Sanguinaria canadensis (Fig. 11), Convallaria majuscula and Carex fraseri.

The USMWST field trip came about after a data capture survey (see Gardner, Frachon \& Rae, 2009, for a description of data capture methods) on the existing collection of Trillium species at RBGE. This revealed that wild collected accessions only accounted for 5 per cent of the collection. The Living Collection Policy at RBGE (Rae et al., 2006) describes the intention to increase the percentage of wild origin material within the Living Collection by 1 per cent every year. The trip in 2011 prioritised the collection of Trillium species and in total we managed to return with seed of around 12 different species. In the long term many of these will be planted out. Ripe seed of Trillium usually requires two years before the germination inhibitors within the seed are broken down and they begin to germinate. Accordingly, the first of these collections 


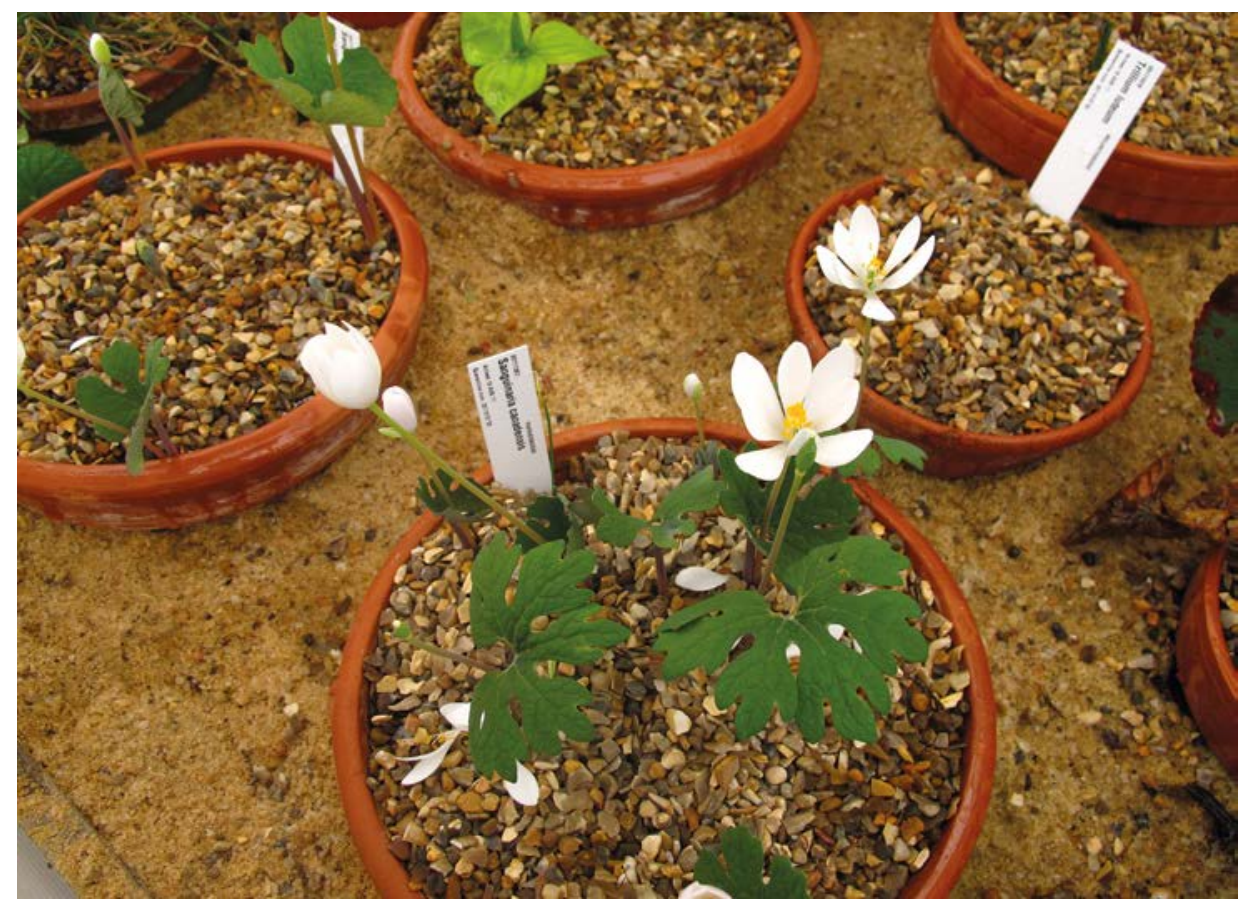

Fig. 11 Sanguinaria canadensis 20111307 growing in the quarantine glasshouse. Photo: Robert Unwin.

started to germinate in the early days of spring 2013. The long process of establishing them as flowering plants has begun.

We were lucky enough to be granted permits to collect living material on the USMWST trip and so were able to collect small numbers of plants from some of the sites where we collected seed. So, in the meantime, some of the live Trillium plants collected will be planted out. To accompany these new plantings a series of interpretation panels will be developed to give information about the area and the plants growing there.

I am eagerly awaiting the release of several plants of Fothergilla major from the quarantine glasshouse. These were also collected as small suckers in North Carolina in 2011 but they only arrived at RBGE in December 2012. Colleagues at Mt Cuba, Delaware, had been kindly establishing these as plants for us since they were collected. They were sent over to us in a dormant state with all traces of soil carefully washed from the roots and with the appropriate collection and phytosanitary certificates from the US authorities. They were cared for in RBGE quarantine facilities for five months. Once they had been passed as free from any pests or disease, they were released as healthy plants, and have now been planted out in the Lower Woodland Garden where they will provide structure to the display.

Over the coming years as plant material from recent and forthcoming collecting trips becomes available from the RBGE Nursery the collection of plants in the area will develop and increase. 


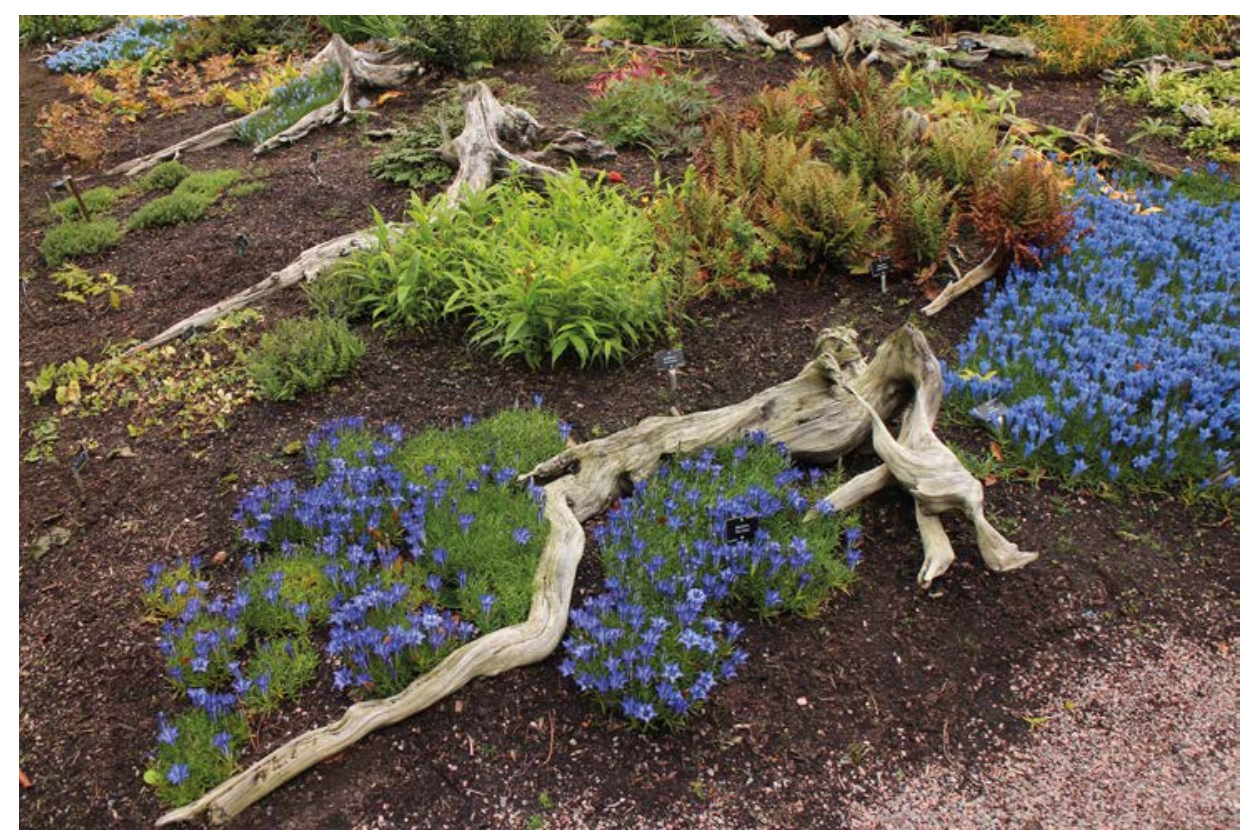

Fig. 12 Gentiana 'The Caley'.

A number of garden origin cultivars have also been planted in the area for their display value. Fig. 12 shows Gentiana 'The Caley', a cultivar of Gentiana sino-ornata bred by East Lothian nurseryman Ian McNaughton and named to celebrate the bicentenary of the Royal Caledonian Horticultural Society.

\section{REFERENCES}

EVANS, A. (1974). The Peat Garden and its Plants. J.M. Dent, London.

FRACHON, N., GARDNER, M.F. \& RAE, D. (2009). The Data Capture Project at the Royal Botanic Garden Edinburgh. Sibbaldia, 7, 77-82.

HAYDEN, P. (1989). Biddulph Grange. Philip/The National Trust, London.

MCDOUALL, K. (1927). The Gardens at Logan. The Journal of the Royal Horticultural Society, 52(1), 1-14.

MCLEAN, B. (2004). George Forrest Plant Hunter. Antique Collectors Club, Spain.

RAE, D., BAXTER, P., KNOTT, D., MITCHELL, D., PATERSON, D. \& UNWIN, B. (2006).

Collection Policy for the Living Collection. Royal Botanic Garden Edinburgh. 